\title{
Recordando la conferencia internacional sobre los principios de catalogación (C.I.P.C.)
}

\author{
Lic. Ofelia Solís Valdespino \\ Investigadora del CUIB
}

Introducción

El propósito de este escrito es presentar una relación muy des criptiva del desarrollo de esta conferencia, con la finalidad de que las nuevas generaciones de bibliotecarios conozcan no solo los objetivos y los documentos que se discutieron, sino la exposición de principios que resultó de la misma.

Con frecuencia encontramos en la literatura de la especialidad referencia a los "Principios de París",. De ellos se dice que constituyen las bases filosóficas de los códigos de catalocación más importantes del mundo (el angloamericano, el soviético, el español, el francés, etc.) ; también se afirma que su redacción se presta a muchas dudas, que es ambigua y da lugar a muchas interpretaciones lo que dificulta su aplicación; otra aseveración es que se han superado por el empleo de la electrónica en las bibliotecas; la propia Federación Internacional de Asociaciones de Bibliotecarios ha publicado en 1971 una edición minuciosa de la Exposición de Principios en la que los analiza y comenta a la luz de los avances en materia de normalización catalográfica.
Pues bien, resulta que la mayoría de los bibliotecarios desconocemos los multicitados "Principios"; posiblemente debido a que los consideramos muy obvios, o creemos que es innecesaria su lectura puesto que se reflejan claramente en el código de mayor aplicación en nuestro país: las Reglas de Catalogación angloamericanas en sus dos ediciones, o tal vez porque forman parte de la historia -cumplieron ya 12 años-y la dinámica de la vida actual nos obliga a actualizarnos constantemente sin contemplar cual es el pasado; no conocemos la historia de las bibliotecas más que a grandes pinceladas y la vemos como parte de una formación académica general, no la conceptuamos como un elemento que nos permita manejar apropiadamente el presente y así no estamos en posibilidades de proyectar el futuro de las tareas de organización bibliográfica en las bibliotecas, archivos y organismos similares. No debemos pasar por alto que nuestra principal tarea como profesionales de la bibliotecología es la organización de la información dentro de adecuados sistemas de almacenamiento y recuperación que responsan eficazmente a los requerimientos de nuestros usuarios.

Quien escribe esto, considera que la catalogación es más que una rutina tediosa (mal necesario para organizar la información bibliográfica), es una disciplina inte- 
lectual que demanda de quien la ejerza además de la adecuada aplicación de normas y una formación académica humanística y enciclopédica, la comprensión de la filosofía y los propósitos subyacentes en el enunciado de las reglas a fin de estar en condiciones de almacenas debidamente la información bibliográfica para su eficiente recuperación con miras a servir a una comunidad, estar en posibilidad de contribuir, mediante el análisis profundo de las normas para la organización y el control bibliográfico internacional, a la elaboración de un código nacional que ofrezca normas acordes a las características de nuestras bibliotecas, sin desvincularse por ello del intercambio de información bibliográfica a nivel internacional; esto sería una importante aportación al cuerpo teórico de conocimientos de una bibliotecología mexicana.

\section{ANTECEDENTES .}

La normalización de la información en la práctica catalográfica ha sido una preocupación fundamental para la Federación Internacional de Asociaciones de Bibliotecarios (en adelante FIAB), quien la considera una herramienta indispensable para el óptimo aprovechamiento de los recursos informativos, y valiosa para facilitar el intercambio de información en sus diferentes niveles: interinstitucional, regional, nacional e internacional. La Conferencia Internacional sobre los Principios de Catalogación, en adelante CICP, tuvo su origen en la inquietud de un grupo de catalogadores quienes en la reunión anual de 1954 de la FIAB, que se llevó a efecto en Zagreb, Yugoeslavia, lograron que el consejo de la FIAB creara un grupo de trabajo cuya labor sería coordinar los principios de catalogación a nivel internacional. (1) A este grupo se le denominó Committee on Uniform Cataloguing Rules; inicialmente lo formaron 8 catalogadores provenientes de países con distintas tradiciones catalográficas; ellos se ocuparon de examinar la coordinación internacional de los principios de catalogación y la observancia de éstos en el establecimiento de asientos principales de obras anónimas de trabajos escritos por autores corporativos. (2)

La UNESCO ha procurado ayuda y estímulo al Comité de Catalogación. Así, el primer informe del comité fue preparado gracias a un contrato de la UNESCO. Se ocupó de las reglas para el establecimiento de fichas principales para obras anónimas y autores colectivos. El texto completo de este informe apareció en la revista Libri, vol. 6, No. 3, 1956. Las conclusiones generales del mismo informe se publicaron en el Boletín de la UNESCO para las bibliotecas, vol. No. 5-6, mayo-junio, 1956.(3)

En 1956 el Council on Library Resources (de Estados Unidos) concedió a la FIAB una subvención que permitió al Comité de Catalogación convocar a una reunión con el objetivo de preparar una conferencia internacional en la que llegara a acuerdos sobre principios básicos en la catalogación. Dicha reunión se llevó a cabo en Londres en julio de 1959.(4)

\section{PREPARACIÓN DE LA CONFERENCIA}

En 1958 y 1959 la FIAB firmó nuevos acuerdos con la UNESCO para estudiar con más detenimiento lo referente a los encabezamientos de obras anónimas y trabajos de autores colectivos, y además, la forma en que deberían tratarse los nom- 
bres propios y los nombres geográficos en los encabezamientos. ( $\%$ ) Cabe señalar que los esfuerzos del Comité de Catalogación de la FIAB no estaban aislados. El camino para la preparación de la Conferencia fue abonado también por la colaboración entre los catalogadores ingleses, norteamericanos y canadienses, quienes se ocupaban intensamente en la revisión del ALA Catalog Code en su edición de 1949 (trabajo que fructificó en el Código angloamericano) son notables los trabajos de los catalogadores franceses, italianos, alemanes y soviéticos en pro de un acuerdo internacional sobre códigos catalográficos. Todo esto dio como resultado, junto con otros factores, la reunión de exploratoria de julio de 1959 en Londres, con representantes de Francia, Alemania, Gran Bretaña, Italia, la Unión Soviética y Estados Unidos. (6)

Del informe de esta conferencia preliminar se desprende la siguiente información. (7)

1.objetivos:

1.1. determinar los aspectos de la catalogación a examinarse durante la Conferencia Internacional, 1.2. definir los objetivos de la Conferencia Internacional de Catalogación, 1.3.fijar fechas y lugar de celebración de la conferencia, 1.4.preparar un proyecto de orden del día para la Conferencia, 1.5.ordenar la preparación y distribución de los documentos de trabajo, 1.6.resolver los problemas de representación, participación, presupuesto y todo lo relativo a la organización definitiva de la Conferencia.

2. Participación:

Veinte catalogadores de diversos países: Gran Bretaña, Italia, In- dia, Unión soviética, Portugal, Japón, Alemania Federal, Australia, Países de Gales, Francia, Estados Unidos.

3.- Documentos de trabajo:

Durante esta reunión se estudiaron 15 documentos, algunos de ellos fueron preparados por miembros del grupo y otros por organizaciones y personas interesadas. La preparación de estos trabajos se costeó mediante contratos establecidos con la UNESCO para proseguir los trabajos del Grupo sobre Catalogación. En noviembre de 1958 a julio de 1959 se distribuyeron cinco boletines en los que se presentaba el trabajo del grupo y las finalidades de la reunión preliminar. La lista de los documentos se da a continuación:

1. "Asuntos que debe examinar una conferencia internacional sobre catalogación", por Ludwing Sickmann.

2. "Principios en que deben basarse las reglas de catalogación", por Wyllis E. Wright y Seymour Lubetzky .

3. "Temas de debate", por S. R. Ranganathan.

4. "Sugestiones relativas a la coordinación de los principios de catalogación", por la Association des archivistes, bibliothecaires et conservateurs de Musées de Belgique.

5. "Nombres compuestos y nombres con prefijos", por Fernanda Ascarelli.

6. "Encabezamiento de las fichas de autores cuyos nombres presentan variantes", por Pvle Kalan. 7. "Los nombres asiáticos en los encabezamientos de fichas cuando se emplee el alfabeto latino", por Benoyendra Sengupta.

8. "Catalogación de las obras con más de un autor en el catálogo alfabético", por Hellmut Braun.

9. "Informe preliminar sobre algunos problemas relativos a los au- 
tores colectivos", por Paul Poindron.

10. "Obras anónimas catalogadas con encabezamientos de grupo y determinantes de forma", por Roger Pierrot.

11. "Organización y alcance de la Conferencia Internacional de Catalogación propuesta", por A. H. Chaplin.

12. "Proyecto de orden del día". 13. "Elementos para el establecimiento de un plan para un catálogo colectivo de literatura hebrea", por R. Edelman.

14. "Informe sobre la situación y los problemas de la catalogación en América Latina", por María Luisa Monteiro de Cunha.

15. "Prácticas japonesas de catalogación", por la Asociación de Bibliotecarios del Japón.

4.- Celebración:

Se celebró la reunión preliminar en Londres, del 19 al 25 de julio de 1959, las reuniones fueron en Chauncer Hose, sede de Library Association. Asistieron doce observadores. Las disposiciones técnicas de esta reunión estuvieron a cargo de Dorothy Anderson con la asistencia de Mary Welch.

5.- Temas:

1.finalidad y alcance de la propuesta conferencia internacional de catalogación y asuntos que debían estudiarse en ella; y

2.composición y organización de la conferencia.

6.- Conclusiones:

Conclusión unánime: existe una base para establecer un amplio acuerdo sobre importantes principios de catalogación. Debe celebrarse la conferencia internacional porque en ella podrían alcanzarse resultados prácticos que facilitarían el acceso a la información bibliográfica y su intercambio internacional.

7.- Objetivo de la conferencia
Debe ser lograr un acuerdo sobre los principios básicos que norman la selección y la forma de los encabezamientos en la ficha del catálogo alfabético de autores y títulos. El examen de esos principios debe basarse en los siguientes supuestos acerca del carácter del catálogo:

1.el catálogo debe perseguir dos objetivos:

1.1.permitir la localización de una publicación determinada por el nombre de su autor o por su título, tal como aparezca en la publicación;

1.2.reunir fichas para todas las ediciones y traducciones de un trabajoy todos los trabajos de un autor;

2. deberá tener una ficha principal para cada tema, con fichas y referencias auxiliares en los casos necesarios.

8.- Temas:

Lista de asuntos sobre los cuales ha de preocuparse lograr acuerdo:

1. Función de la ficha principal.

2. Contenido de la ficha principal.

3. Autores individuales.

4. Autores colectivos.

5. Fichas de título.

6. Determinantes de forma.

Como base para los trabajos de la Conferencia deben emprenderse los siguientes estudios:

7. Estudio de las relaciones existentes entre los principios de catalogación en las bibliotecas y los que rigen en otras formas de información bibliográfica.

8. Compilación de una serie de definiciones de conceptos necesarios para formular principios de catalogación en términos equivalentes en varios idiomas.

9. Estudios de las diferentes clases de nombres no europeos, en especial los nombres islámicos y los diversos grupos de nombres indios, a fin de coordinar las for- 
mas en que esos nombres se utilizan en los catálogos. Tales estudios se realizarán con la ayuda de grupos de trabajo establecidos en los países y regiones correspondientes.

10. Estudio del problema de la transcripción en lo que se refiere a los encabezamientos en los catálogos de bibliotecas.

11. Estudios sobre la forma en que deben figurar en los encabezamientos los nombres compuestos y los nombres con prefijos, con miras a unificar los métodos utilizados en las principales lenguas europeas. Estos estudios se basarán en consulta entre expertos de países que tengan el mismo idioma.

12. Estudio de los problemas que plantea la catalogación de textos litúrgicos y otros textos religiosos en el catálogo alfabético. 13. Estudio de los problemas relativos a las fichas de las publicaciones que forman parte de colecciones.

\section{9.- Fechas:}

La Conferencia se celebrará en París en 1961, preferentemente en abril o en septiembre y durará diez días.

10.- Participación:

deberán estar ampliamente representadas organizaciones de las siguientes categorías:

13.1.asociaciones regionales y nacionales de bibliotecarios

13.2.organizaciones internacionales que se ocupen de bibliotecología, bibliografía y edición y venta de libros,

13.3.bibliotecas nacionales cuyos catálogos tengan una influencia importante en lo referente a prácticas de catalogación.

13.4.Organismos responsables de bibliografías nacionales y catálogos colectivos,

13.5.Organismos oficiales que fiscalizan y subvencionan las bi- bliotecas y las actividades bibliográficas.

Los representantes deberán estar capacitados para intervenir y votar en nombre de las organizaciones que les hayan designado.

También podrán invitarse a expertos que participen a título personal.

Para facilitar el trabajo de la Conferencia, se celebrarán previamente debates conjuntos sobre los asuntos que se tratarán en ella en aquellos países donde existan varias organizaciones interesadas. De no haber tales organizaciones, será de utilidad que se agrupen varios países para debatir conjuntamente los temas. El Comité de Organización tomará las decisiones definitivas en cuanto a participación y representación considerando los recursos económicos de que se disponga: 11. - Todos los preparativos y disposiciones administrativas se encomiendan a un secretario ejecutivo, a quien se le agregará el personal necesario, y a un reducido comité de organización a cuyo cargo estarán las cuestiones de orientación general:

12. - Se encargará a redactores la preparación de documentos de trabajo sobre cuestiones concretas, y en algunos casos habrá grupos de trabajo que ayuden a los redactores; esto se refiere a los estudios que deberán emprenderse según el punto 8. En cada uno de esos documentos se analizará brevemente el problema, se expondrán las diversas soluciones posibles y se harán recomendaciones. Los documentos se comunicarán ampliamente para sus comentarios antes de darles forma definitiva. Después se preparará un proyecto de declaración de principios, basado en las recomendaciones de los documentos de trabajo, que se someterá a la conferencia. 
13. - El éxito de los trabajos de la Conferencia dependerá en gran parte de los servicios y posibilidades materiales de que se disponga tanto en lo referente a salas de reunión adecuadas y servicios de traducción y reproducción de documentos como a interpretación en varios idiomas. Por consiguiente, los miembros asistentes a la reunión preliminar piden al consejo de la Federación Internacional de Asociación Internacional de Asociaciones de Bibliotecarios que consulte al Director General de la UNESCO sobre la posibilidad de disponer de loscales y servicios técnicos para la Conferencia en la Casa Central de la UNESCO en $\mathrm{Pa}-$ rís, costeando tales servicios la FIAB :

14.- Los asistentes a la reunión piden al Secretario de la FIAB que solicite al Council on Library Reources una nueve subvención que junto con otros recursos, permita enfrentar los gastos de celebración de la Conferencia. Encargaron al Comité de Organización que prepare un presupuesto que servirá de base para solicitar la subvención.

\section{CELEBRACIÓN.}

Del 9 al 18 de octubre de 1961 se llevó a cabo la CICP; fue sede la Casa de la UNESCO en París.

Su objetivo fue: "Llegar a un acuerdo sobre los principios fundamentales relativos a la elección y forma del encabezamiento en el catálogo alfabético de autores y títulos."(8)

El Comité Organizador, nombrado en la Reunión Preliminar de londres, estuvo constituido por:(9)

Sr. Paul Pindron, Conservador Jefe de la Direction des Bibliotheques de France, Paris (Vice-Presidente)

Dr. Ludwig Sickmann, Conservador, Bibliothekar Lehrinstitut des
Landes Nordrhein Westfalen. Cologne.

Srita. N. A. Lavrova, Secretaria Científica y Jefe de Bibliografía de la Cámara del Libro, Moscú.

Sr. A. H. Chaplin, Conservador, Department of Printer Books, British Mosem, Londres (Secretario Ejecutivo) y durante la conferencia se agregaron las siguientes personas: (10)

Sra. Maria Luisa Monteiro de Cunha, Directora de la Biblioteca Central de la Universidad de Sao Paulo, Brasil.

Dr. Andrew Osborn, Bibliotecario University of Sydney, Australia.

Shri Benoyendra Sengupta, Bibliotecario Asistente, National Library, Calcutta.

Sr. Wyllis E. Wright, Bibliotecario, Williams College. Williamstown, Massachusetts.

Las Delegaciones. (11) Asistieron 105 participantes en total, entre los cuales hubo reoresentantes de 53 países, de 12 organizaciones internacionales ligadas a asuntos bibliotecarios, bibliográficos y editoriales, los miembros de la Comisión Organizadora y los autores de los trabajos nombrados por la Comisión. Los observadores fueron 104 y provenían de 20 países.

Las naciones que enviaron representación fueron: África Occidental, Argentina, Australia, Austria, Bélgica, Brasil, Bulgaria, Canadá, Ceilán, Colombia, Corea (República), Checoeslovaquia, Chile, China (República), Dinamarca, España, Estados Unidos, Findandia, Francia, Guatemala, Holanda, Hungría, India, Indonesia, Irán, Israel, Italia, Jamaica, Japón, Líbano, Luxemburgo, México, Noruega, Nueva Zelandia, Pakistán, Perú, Polonia, Portugal, Reino Unido, República Federal Alemana, República Sudafricana, Rhodesia y Nyasalandia 
(Federación), Rumanía, Singapur, Suecia, Suiza, Tailandia, Turquía, URSS, Uruguay, Vietnam (República), Vietnam (República Democrática), Yugoeslavia.

No pudieron asistir los delegados de Cuba, República Democrática Alemana, ni la República Árabe Unida.

Hubo representantes de las siguientes organizaciones internacionales:

Asociación Internacional de Bibliotecas Judaicas y Hebraicas en Europa, Federación Internacional de Documentación, Biblioteca de la FAO, Asociación Internacional de Bibliotecarios y Documentalistas Agrícolas, Asociación Internacional de Bibliotecas Jurídicas, Asociación Internacional de Bibliotecas Musicales, Federación Internacional de Normalización, Unión Internacional de Editores. Biblioteca de las Naciones Unidas, Nueva York, Biblioteca de las Naciones Unidas, Ginebra y UNESCO.

Dinámica de trabajo: (12) La base para el desarrollo de las sesiones lo constituyó el Anteproyecto de Exposición de Principios. Este documento estaba dividido en 13 secciones numeradas progresivamente. Cada sección contenía puntos numerados progresivamente. En el programa de trabajo se señalaban aquellas secciones del anteproyecto que serían discutidas en cada sesión, así como las ponencias correspondientes y los autores de las mismas. No se leían las ponencias.

El procedimiento era:

1.Abrir la discusión general, podían intervenir todos los participantes y aún los autores de las ponencias. Las intervenciones podían ser en representación de una delegación nacional, de una orga- nización o a título personal y no excedían de cinco minutos.

2. Las delegaciones nacionales podían presentar adiciones y enmiendas por escrito al Presidente antes de que finalizara la discusión.

3. Una vez que se daba por terminada la sesión, el Presidente designaba grupos de trabajo que debían examinar las propuestas, adiciones, enmiendas y comentarios a fin de preparar un texto revisado de la sección correspondiente que sería sometido a votación en una sesión posterior. Los grupos de trabajo estaban formados por personas que manifestaban puntos de vista diferentes dentro de cada sección, más los miembros de la comisión organizadora.

4. Distribución del texto revisado de cada sección previo a la sesión de votación.

5. Votación de los textos revisados de las diferentes secciones del anteproyecto.

Se formaron grupos especiales de trabajo para los asuntos siguientes: Terminología, Transliteración, Bilingüismo, Nombres indios, Nombres Mahometanos en India y Pakistán, Nombres árabes, Nombres hebreos, Nombres persas, Liturgia. (13)

Programa de Trabajo: Se basó en el Anteproyecto de Exposición de Principios: este documento estaba dividido en 13 secciones, a saber: 14 )

1. Alcance y fines de la exposición.

2. Funciones del catálogo.

3. Estructura del catálogo.

4.Clases de asientos.

5. Empleo de asientos múltiples.

6. Función de las diferentes clases de asientos.

7. Elección del encabezamiento uniforme.

8. Autor personal único. 
9 Asiento bajo nombres de entidades.

10 Autores múltiples.

$11.0 b r a s$ catalogadas por título. 12. Encabezamientos y subencabezamientos de forma.

13. Encabezamientos para los nombres compuestos, nombres con prefijos y nombres orientales.

Agenda. (15)

Lunes 9

Cuestiones generales, Influencia de los sistemas electrónicos.

Propuesta de Exposición de Principios.

--Sección 1. Alcance y fines de la exposición.

--Sección 2. Funciones del catá$\log \circ$.

--Sección 3. Estructura del catá$\log 0$.

Documentos de trabajo:

Ponencia No. 17. "El impacto de la electrónica en reglas de catalogación". Por C. D. Gull.

Martes 10

Dos secciones generales.

--Sección 4. Clases de asientos.

--Sección 5. Empleo de asientos múltiples.

--Sección 6. Función de las diferentes clases de asientos.

--Sección 7. Elección del encabezamiento uniforme.

--Sección 8. Autor personal úni$\mathrm{CO}$.

Documentos de trabajo:

Ponencia No. 1 "Relación entre los principios de catalogación y los aplicables a otras formas de trabajo bibliográfico". Por Andrew D. Osborn.

Ponencia No. 2. "La función del asiento principal en el catálogo alfabético". Por Symour Lubetzky. Ponencia No. 3. "La función del asiento principal en el catálogo alfabético". Por Eva Verona.

Ponencia No. 4. "La función del asiento principal en el catálogo alfabético; un estudio de los pun- tos de vista propuestos por Lubetzky y Verona". Por Leonard J. Jolley.

Ponencia No. 11. "Elección de encabezamientos para autores cuyos nombres varían". Por Pavle Kalan. Miércoles 11.

Una sesión general.

--Sección 9. Asiento bajo nombres de entidades.

Subsecciones $9.1-9.3$

Documentos de trabajo:

Ponencia No. 5. "Autores corporativos I. A) límites en el uso de asientos bajo autores corporativos; b) catalogación de documentos legislativos y tratados". Por V. A. Vasilevskaya.

Ponencia No. 6. "Autores corporativos II. A) forma de los encabezamientos; b) tratamiento de entidades subordinadas". Por Suzanne Honoré.

Ponencia No. 9. "La catalogación de textos litúrgicos y otros textos religiosos en el catálogo alfabético". Por Ruth C. Eisenhart. Ponencia No. 11. "Elección de encabezamientos para autores cuyos nombres varían". Por Pavle Kalan. Jueves 12 .

Una sesión general.

--Sección 9. Asiento bajo nombres de entidades

Subsección $9.4-9.5$

Documentos de trabajo:

Ponencias Nos. 5, 6, 9 y 11.

Viernes 13.

Dos sesiones generales

--Sección 10. Autores múltiples.

--Sección II. Obras asentadas por título.

Documentos de trabajo:

Ponencia No. 7. "Obras anónimas catalogadas bajo títulos uniformes". Por Roger Pierrot.

Ponencia No. 8. "Problemas de la catalogación de series". Por Paul S. Dunkin.

Ponencia No. 9 "La catalogación de textos litúrgicos y otros textos 
religiosos en el catálogo alfabético". Por ruth C. Eisenhart.

Ponencia No. 10. "Autores múltiples". Por Hellmut Braum.

Sábado 14.

Dedicada a Grupos Especiales de

Trabajo.

Lunes 16.

Dos sesiones generales.

--Sección 12. Encabezamientos y subencabezamientos de forma.

Documentos de trabajo:

Ponencia No. 13 "Tratamiento de nombres brasileños y portugueses". Por María Luisa Monteiro de Cunha.

Ponencia No. 14. 2El tatamiento de los nombres indios en el catálogo". Por Benoyendra Sengupta.

Ponencia No. 15. "El tratamiento de los nombres árabes". Por Mamad Sheniti.

Ponencia No. 16. "El tratamiento de los nombres en caracteres hebraicos y el asiento bajo título para libros hebreos". Por R. Edelmanr.

Martes 17.

Una sesión general.

Examen de diversas proposiciones para acciones futuras.

Miércoles 18.

Una sesión general.

Resoluciones finales de la Conferencia.

--Clausura.

En cuanto a las actividades de los prepresentantes de países hispanoamericanos, Poves B. relata:

"El día 10 tuvo lugar una reunión de los delegados de Argentina, Colombia, Chile, España, Guatemala, México sic., Perú y Uruguay, para precisar la terminología española sobre catalogación. La Comisión española de catalogación había remitido al Comité organizador de la Conferencia, como ya he dicho, una lista de términos españoles. Esta lista y otra compilada por la señorita Emma Linares, delegada de Argentina, sirvieron de base par la discusión que se desarrolló en un ambiente de total compenetración y simpatía. Los acuerdos fueron unánimes.

El día 18, los delegados de España $y$ los países hispanoamericanos acordaron constituir un grupo de trabajo para tratar de resolver los problemas de catalogación propios de nuestro idioma. Este acuerdo fue comunicado al secretario del comité organizador de la conferencia en una carta firmada por todos. En ella se expresaba, también, el deseo de mantener contacto con dicho comité para darle cuenta de los trabajos realizados." (16)

Respecto del contenido de las ponencias, se presenta una breve descripción basada en la información que Poves Bárcenas proporciona en su documento.(17)

\section{PONENCIAS}

PONENCIA No. 1: Andrew D. Osborn. "Relación entre los principios de catalogación y los aplicables a otras formas de trabajo bibliográfico." 1) Su propósito es apoyar las bases formuladas por Lubetzky en code of cataloguing rules a fin de vincular la catalogación con la bibliografía y con el comercio de libros. 2) Para lograr esta aproximación, se precisa que los catálogos de bibliotecas prescindan de algunos tecnicismos. 3) Considerando que en muchas lenguas el nombre del autor va precedido de la proposición por o sus equivalentes, al elegir el nombre para el encabezamiento de la ficha principal, debe atenderse a los nombres que en las portadas vayan precedidos de esta manera. 4) Debe preferirse el nombre más conocido. 5) Para las publicaciones gubernamentales debe comenzar el asiento por el nombre del autor corporativo, no por el 
lugar. 6) Los códigos de catalogación están de acuerdo en reconocer las obras anónimas; pero es necesario reconocer la existencia de otra categoría de obras que se publican sin título y que son cada día más numerosas.

PONENCIA No. 2, 3 y 4: Seymour Lubetzky, Eva Verona y Leonard J. Jolley. "Papel de la ficha principal en el catálogo alfabético." (los tres abordaron el mismo tema). En la Reunión Preliminar de Londres, 1959, se determinó que los fines del catálogo son dos: 1) Localizar una publicación particular por el nombre de su autor o por su título tal como figura en la publicación; 2) Agrupar las fichas de todas las ediciones y traducciones de una obra y todas las obras de un autor. Se presentan dos problemas: cuando un autor publica bajo diferentes nombres y cuando una obra se ha publicado con diferentes títulos. En el primer caso los 3 autores coinciden en afirmar que todas las obras de un autor deben reunirse en el catálogo bajo un solo encabezamiento; y respecto al segundo problema, Lubetzky propone que se escriba siempre en título original en el encabezamiento. Verona opina que los títulos originales deben adoptarse siempre para los clásicos anónimos, no así para los anónimos modernos que son mejor identificados por los títulos de las distintas ediciones o traducciones. Jolley intenta conciliar estas dos opiniones contradictorias.

PONENCIA No. 5: V. A. Vasevskaya "Autores corporativos I. A) límites en el uso de los asintos bajo autores corporativos: b) catalogación de documentos legislativos y tratados." Los códigos nacionales de los diversos países, excep- ción de Alemania y Austria, coinciden al considerar a las entidades como autores colectivos responsables de sus publicaciones. Así pueden agruparse en el catálogo las obras de una entidad tanto en fichas principales como secundarias. Se hace una comparación de las normas de la Unión soviética con las de la American Library Association. En las primeras el criterio seguido para que el nombre de la entidad figure en el asiento de la ficha principal depende del contenido de la obra, de su destino y de su carácter. Así se catalogan bajo una entidad sus publicaciones oficiales: declaraciones, situación, información, etc. Las normas de ALA son más amplias: el nombre de la entidad encabeza la ficha principal no sólo de las publicaciones que reflejan sus actividades, sino también de aquellas de que la entidad es responsable. En cuanto a los documentos legislativos que se asientan por el nombre del país respectivo según los códigos actuales, propone que al nombre del país se añada un subencabezamiento de forma: constitución, leyes y decretos, etc.

PONENCIA No. 6: Suzanne Honoré. "Autores corporativos II. A) forma de los encabezamientos; b) tratamiento de entidades subordinadas." Considera dos cuestiones fundamentales en la catalogación de las obras debidas al trabajo colectivo de los miembros de una entidad: I. Forma de los encabezamientos; II. Entidades subordinadas a otras.

1. Forma. Al igual que los autores individuales, las entidades deben figurar en los encabezamientos bajo la forma adoptada en su país de origen. 1) Propone suprimir el término "encabezamiento geográfico" que puede dar lugar a confu- 
siones, ya que los nombres de los Estados no coinciden siempre con la geografía; 2) Del mismo modo, producirán confusión los encabezamientos de forma, tanto si sustituyen al nombre de la entidad como si se mezclan con él. En las constituciones, leyes, etc., de un país, mejor que añadir al nombre del Estado un encabezamiento de forma, es poner un título convencional, entre corchetes, antes del título de la obra; 3) Para la determinación del nombre de la entidad se presenta el problema de la elección entre el nombre que figura en la publicación, el oficial de la entidad o el más conocido. La forma que ofrece más garantías para el futuro es la oficial, aún teniendo el inconveniente de que el ocasiones resulta difícil determinarla. El uso del nombre más conocido puede limitarse a ciertas entidades universalmente conocidas, por ejemplo, la UNESCO; 4) Las publicaciones oficiales de los gobiernos se encabezarán por el nombre del lugar; 5) Ciertos códigos de catalogación determinan que después del nombre de la entidad se escriba el lugar en que radica, siempre que haya que distinguir dos o más entidades que lleven el mismo nombre. La autora cree que es mejor jacer esta adición desde el principio en todos los casos, existan o no entidades homónimas en el catálogo; 6) La mayor parte de las normas nacionales suprimen del principio del encabezamiento los adjetivos honoríficos y los artículos. Las iniciales de nombres propios y los nombres deben conservarse al principio, excepto en las firmas comerciales; 7) El nombre de la entidad debe figurar en el idioma del país de origen. En el caso de entidades que aparecen en varias lenguas oficiales se debe elegir una de ellas y redactar re- ferencias de las demás; 8) Cuando una entidad cambia de nombre hay que considerar si cambia al mismo tiempo de estructura.

II. Entidades subordinadas a otras; debe considerarse que: 1) A veces no hay verdadera subordinación, sino simpli afiliación o confederación de organismos, donde cada uno conserva su autonomía. En estos casos, se encabeza directamente por los nombres de cada entidad; 2) Cuando las entidades no son autónomas, las normas de los diversos países no están de acuerdo, si bien va ganando terreno la práctica de admitir el nombre de la entidad subordinada directamente en los encabezamientos; 3) Si hay más de una entidad subordinada se prescinde generalmente, de las intermedias, y se escriben en los encabezamientos solamente los nombres de la primera y de la última; 4) Propone anteponer en los encabezamientos el "término funcional" al administrativo. Ejemplo: UNITED STATES. Defense Department.

PONENCIA No. 7: Roger Pierrot. "Obras anónimas catalogadas bajo títulos uniformes." I. Si se admite el principio que todas las obras de un autor, incluyendo las que se han publicado anónimamente, con seudónimos o con un nombre distinto del usual, figuren en el catálogo con el mismo encabezamiento, hay que reunir también bajo el mismo título, todas las ediciones, totales o parciales, y todas las traducciones de una obra anónima. Esto supone la elección de títulos, reales o tradicionales, que pueden ser distintos de los que figuran en las obras que se están catalogando con el consiguiente abandono de la norma general, según la cual, estas publicaciones deben ser catalogadas por la primera palabra del tí- 
tulo. Afecta esta regla: a) A los "clásicos anónimos"; b) A las obras anónimas publicadas con títulos distintos en ediciones sucesivas o en traducciones; c) A las publicaciones con títulos convencionales, por ejemplo, los manuscritos del Mar Muerto. El autor propone para estas tres categorías de obras, el uso de títulos de agrupación.

II. Encabezamientos de forma. No son lo mismo que los de agrupación, ya que mientras éstos reúnen bajo un solo encabezamiento las diversas ediciones y traducciones de una obra, los encabezamientos de forma agrupan publicaciones de la misma forma o tipo, pero de distinto contenido y que son difíciles de encontrar en el catálogo, por llevar un título poco significativo. En este grupo incluye el autor de la ponencia los homenajes, catálogos anónimos de bibliotecas privadas, tratados internacionales, catálogos de ventas, etc.

PONENCIA No. 8: Paul S. Dunkin. "Problemas de la catalogación de series." Se inicia la ponencia con una nota del Comité organizador de la Conferencia, en la que se explica que el documento se refiere a las publicaciones periódicas, cuyas fichas se han de intercalar en un catálogo general de autores y obras anónimas. Para un catálogo especial de publicaciones periódicas, pueden adoptarse normas diferentes. A continuación, el autor considera dos cuestiones: A) Elección del encabezamiento para publicaciones periódicas, cuyo título cambia; B) Uso de los encabezamientos con nombres de entidades en publicaciones periódicas.

1.Elección de encabezamiento. Pueden seguirse tres procedimientos: 1) Por título original; 2)
Por el más reciente; 3) Por cada uno de los títulos sucesivos. El autor analiza las ventajas e inconvenientes de cada uno de los tres procedimientos: rechaza el segundo, que obliga a rehacer toda la ficha a cada cambio del título, y se inclina por el encabezamiento por cada uno de los títulos sucesivos o bien por el primero.

2. Encabezamientos con nombres de entidades. Las publicaciones periódicas editadas por una entidad, solamente cuando traten asuntos relativos a la marcha de la misma. En los demás casos, se catalogarán por el título.

Ponencia No. 9: Ruth C. Eisenhart. "La catalogación de textos litúrgicos y otros textos religiosos en el catálogo alfabético." La ponencia analiza dos cuestiones distintas: A) Textos litúrgicos;

B) Libros Sagrados.

3. Textos litúrgicos. Su catalogación ofrece grandes dificultades. Entre las soluciones propuestas a los diversos problemas por la Biblioteca Vaticana de la ALA, existen notables diferencias. Generalmente, los libros litúrgicos son conocidos por títulos tradicionales, y según estos títulos los catalogan quienes no aceptan el concepto de autores colectivos. Sin embargo, parece más apropiado catalogarlos por los organismos eclesiásticos que los autorizan oficialmente. La autora cree que para agrupar las distintas ediciones cuando se trata de bibliotecas pequeñas, puede servir, sencillamente, el nombre del organismo que hace la publicación. En las bibliotecs grandes, la solución puede ser el uso de subencabezamiento de forma "Liturgia y ritual". Ejemplo: Iglesia católica-Liturgia y ritual. Otra solución sería escribir directamente el título tradicional del 
libro que se cataloga como título de agrupación, sin intervención del expresado subencabezamiento de forma. Así, Iglesia católicaMisal, y no Iglesia católica-Liturgia y ritual-Misal.

La identificación de la confesión es un elemento esencial para encabezamientos homónimos. En cuanto al idioma, parece lógico que se use la lengua oficial de la liturgia correspondiente. Sería interesante la redacción de una guía de nombres de entidades religiosas.

B) Libros sagrados. Para éstos se aplican generalmente, las reglas de los "clásicos anónimos". En cuanto a la Biblia el problema más difícil para la unificación es el relativo a los libros pócrifos o deuterocanónicos.

PONENCIA No. 10: Hellmut Braum. "Autores múltiples." En la realización de una obra, hay que distinguir entre la actividad principal (redacción de un texto, composición de una obra musical, creación de una obra de arte) y las actividades secundarias: editor literario, traductor, ilustrador, etc. El autor es el creador de un texto, y lleva la responsabilidad del contenido del mismo: igual responsabilidad corresponde al artista creador. Las entidades se consideran, también, como autores personas jurídicas o morales.

En las obras escritas en colaboración, unas veces se distingue la aportación de cada colaborador (joint autor), y otras veces no se distingue (composite work). La catalogación puede ser igual para ambos casos siempre que exista un solo título para toda la obra. Si los autores aparecen en la portada como colaboradores iguales, sin destacar ninguno, la ficha principal se encabezará por el que figure en primer lugar en la portada, siempre que no sean más de tres, para los siguientes se redactarán fichas secundarias. En el caso de que los autores sean más de tres, se catalogará la obra por el título, y se redactarán fichas secundarias por los tres colaboradores primeros. Cuando la colaboración de cada autor se indica en la portada, si hay un título colectivo, se catalogará por él; si no lo hay, elegirá para encabezamiento de la ficha principal l nombre del autor nombrado en primer lugar en la obra.

Los homenajes y otras obras de parecido alcance en que colaboran mas de tres autores, se deben catalogar por el título, con ficha secundaria del nombre de la persona a quien está dedicado el trabajo. Las antologías, crestomatías, cancioneros, etc., se catalogarán por el título; se redactará una ficha secundaria del compilador. Solo en el caso de que el compilador haya transformado completamente los textos, se encabezará por la que figure en primer lugary en el caso de más de tres, por el título. El mismo procedimiento se seguirá en las conversaciones, diálogos y debates. Para las entrevistas, los códigos de los diversos países no están de acuerdo entre la elección de la persona que expone las ideas y las que las transcribe. Parece conveniente encabezar la ficha principal por la primera, si se reproducen literalmente sus palabras, y por la segunda, si es una interpretación libre. Se presenta el mismo problema y se da la misma solución cuando un texto ha sido redactado según documentos escritos con anterioridad; diarios, notas, etc. Las relaciones de viajes o expediciones se catalogarán por el autor del texto aunque no sea el responsable de la expedición. De éste se redactará una ficha secundaria. 
Cuando los diversos autores de una obra han colaborado cronológicamente se catalogará por el primer autor. Las continuaciones y suplementos que han sido publicados aisladamente con la indicación de esta circunstancia en la portada, se catalogarán por el autor de la continuación con ficha secundaria del autor de la obra primitiva. La solución inversa se aplicará solamente cuando la continuación, etc., está unida a la obra primitiva por una numeración continua. Las adaptaciones libres, refundiciones de piezas, de teatro, adaptaciones en verso, etc., deben ser catalogadas por el adaptador a menos que, por la redacción del título se vea claro que el autor primitivo debe ser considerado como autor principal. Las obras compuestas de texto y láminas se catalogarán por el autor del texto cuando la parte artística se haya incluido como mera ilustración del texto. Si lo principal son las láminas, se encabezará la ficha principal por el artista. Los libretos de obras musicales se catalogarán por el autor de la música, aunque no vayan acompañados de ésta en la obra que se cataloga.

PONENCIA No. 11: Pavle kalan. "Elección de encabezamientos para autores cuyos nombres varían." Para que en el catálogo todas las obras de un autor estén reunidas en un solo lugar, es necesario que los encabezamientos de todas las fichas sean iguales.

La dificultad surge cuando un autor es conocido por más de un nombre, y va aumentando a medida que aumenta el número de nombres que designan al mismo autor. La autora estudia detenidamente las soluciones ofrecidas en los diversos códigos nacionales de catalogación a los problemas referentes a la elección del encabezamiento para los autores identificados en sus obras de varias formas y, en particular, a los cambios de nombres. Del estudio deduce los siguientes principios: 1) Las obras de un autor cuyo nombre varía debe catalogarse, generalmente, por el nombre más conocido; 2) Siempre que sea posible, se preferirá el nombre que conste en las obras del autor, a menos que sea más conocido por otro; 3) Las obras de un autor que ha cambiado de nombre legalmente se catalogarán por el último nombre, cuando no sea más conocido por otro; 4) En el caso de las mujeres que al casarse cambian su apellido por el del marido, se tomará este nombre para el encabezamiento de las fichas principales, siempre que no sean más conocidas por otro nombre; 5) Para los miembros de órdenes religiosas que han escrito con el nombre de religión y con el suyo, combinados, se escribirá primero el nombre de familia y después el de religión; pero si usan un solo nombre de religión, las fichas se encabezarán por él; 6) Los papas y los antipapas se catalogarán por sus nombres pontificiales, en latín; 7) Las obras de escritores pertenecientes a la nobleza se catalogarán por el determinativo del título, a menos que los autores sean más conocidos por el nombre; 8) Para los autores que han traducido sus nombres al griego o al latín se preferirá la forma adoptada, siempre que no sean más conocidos por el nombre original; 9) Si un autor ha usado constantemente un seudónimo y es conocido por él, se tomará este seudónimo para los encabezamientos de las fichas principales. Pero si ha usado varios seudónimos se preferirá el nombre verdadero; 10) Cuando dos o más autores han escrito con un solo seudónimo, el encabezamiento será este seudóni- 
mo; 11) Un sobrenombre encabezará las fichas, si el autor es conocido generalmente por él; 12) Cuando una entidad cambia de nombre se catalogará por el nombre que use en la época de la publicación, y se redactarán referencias de los otros nombres; 13) Si el nombre oficial de una entidad es poco conocido se preferirá el nombre más popular; 14) Cuando la ortografía de los nombres es anticuada se sustituirá por la moderna en los encabezamientos; 15) A veces, se encuentran dificultades para la elección del nombre, en estos casos se elegirá de acuerdo con los repertorios bibliográficos apropiados; 16) Siempre que los nombres elegidos para encabezamientos de las fichas principales difieran de los que constan en la obra que se cataloga, se redactarán las referencias correspondientes.

A fin de facilitar la cooperación internacional en los servicios de las bibliotecas, la autora recomienda que la Conferencia publique: a) Una lista tipo de las formas aprobadas para los autores conocidos cuyos nombres han cambiado; b) Una lista tipo de obras de referencia.

PONENCIA No. 12: Fernando Ascarelii. "Reporte sobre nombres compuestos y nombres con prefijos." En una nota preliminar se determina que para los nombres compuestos y los nombres precedidos de partículas, el principio básico es que se siga el uso de cada país. A continuación se consideran los problemas que presenta la aplicación de este principio básico cuando los autores tienen nombres de origen extranjero. El problema corresponde especialmente, a los nombres con prefijos. Se consideran cuatro soluciones: 1) Adoptar el uso general de la lengua de la partícula; 2) Adoptar el uso general del país del que es ciudadano el autor; 3) Adoptar el uso general del país del que el autor es originario; 4) Adoptar el uso general de la lengua en la cual el autor escribe habitualmente.

En la ponencia se considera el problema referente a la parte que debe empezar el encabezamiento en los casos de nombres compuestos y nombres con partículas. Puesto que la práctica no es igual en todos los países, se debe seguir la recomendación anotada en la Reunión de Londres de 1959, de adoptar el uso nacional de cada país. Siguiendo este principio básico, la autora da a conocer las normas establecidas en sus países respectivos para los escritores franceses, italianos, portugueses y brasileños, españoles, ingleses, escandinavos, alemanes, húngaros, holandeses y belgas, especialmente en lo que afecta a nombres compuestos y nombres con partículas.

Al final, analiza los problemas expuestos en la nota preliminar y las soluciones propuestas para las comisiones nacionales de diversos países.

PONENCIA No. 13: María Lusa Monteiro de Cunha. "Tratamiento de nombres brasileños y portugueses." Da cuenta de los trabajos realizados en Brasil para resolver los problemas de la catalogación de las obras de escritores brasileños y portugueses, y expone las soluciones a los mismos, después de realizar un estudio comparativo de las reglas propuestas por las diversas "Comisiones del Estado." En el Anteproyecto se modifican las reglas de las instrucciones españolas sobre escritores portugueses, cuyas obras se deben catalogar por el segundo apellido, que, gene- 
ralmente, es el paterno, excepto cuando se tenga la seguridad de que el apellido que va en primer lugar es el del padre, en cuyo caso se encabezarán las fichas por él. En ambos casos se redactarán referencias.

PONENCIA No. 14: Benoyendra Sengupta. "El tratamiento de los nombres indios en el catálogo." Este documento de trabajo va precedido de una introducción firmada por A. H. Chaplin, quien pone de relieve la dificultad de una elección apropiada para el encabezamiento de los nombres de la India, y considera las soluciones propuestas por S. R. Ranganathan y B. Sengupta.

La ponencia estudia los problemas concernientes a los nombres de autores de la India pertenecientes a diversos grupos religiosos y linguísticos, con excepción de los autores mahometanos y cristianos. Para el estudio considera dos periodos: A) Escritores antiguos y de la Edad Media; B) Autores modernos (nacidos después de 1950). Analiza lo establecido en algunos códigos de catalogación, como los de ALA, Vaticana, Etc., y propone soluciones a los diversos problemas. Es de desear que para los escritores orientales cuyos problemas de catalogación se estudian en esta ponencia y en las dos siguientes, se siga la norma básica de adoptar la práctica de los países retrospectivos.

PONENCIA No. 15: Mamad Sheniti. "El tratamiento de los problemas árabes." Estudia los problemas referentes a los nombres árabes en cinco partes: A) Componentes de los nombres árabes; B) Tratamiento de los nombres en las fuentes islámicas; C) Tratamiento de los nombres árabes en los códigos de catalogación existentes; D) Los nombres árabes modernos; E) Propuestas para los encabezamientos de nombres árabes.

PONENCIA No. 16: R. Edelmann. "El tratamiento de los nombres en caracteres hebraicos y el asiento bajo título para libros hebreos." En tres partes estudia los problemas concernientes a la catalogación de las obras de escritores hebreos: a) nombre del autor en hebreo; b) nombres de autor en transliteración; c) fichas por el título.

PONENCIA No. 17: C. D. Gull. "El impacto de la electrónica en las reglas de catalogación." (18) El objetivo de este trabajo es explorar el impacto de la electrónica sobre las reglas de catalogación para que los participantes en la Conferencia consideran la posibilidad de información presentada en forma de materiales no libro, la autoridad automatizada y la catalogación en la máquina. Propone un formato para el almacenamiento y recuperación de la información catalográfica sugiriendo que las normas propuestas sean incluidas como uno más de los apartados dentro de los principios de catalogación, y posteriormente en los códigos catalográficos.

[Aborda los problemas que se discutieron ampliamente en la elaboración de formatos como el ISBD, MARC. En realidad, de haber sido tomada en consideración esta propuesta por los conferencistas, se habría logrado un progreso significativo en lo concerniente a la automatización de los procesos técnicos.]

Como reflejo de la época, la conferencia prestó poca atención sobre este punto, y antes de trascurridos unos 10 años, la computadora estaba ya presente en las bibliotecas y las posibilida- 
des que habría para los catalogadores eran impresionantes, se hizo necesaria una reconsideración de las normas a fin de aprovechar las posibilidades de la automatización en la elaboración de archivos en computadoras. Se hicieron simplificaciones para abandonar frases descriptivas (Pres. U. S.) que podrían obstaculizar la alfabetización mecánica. (19)

\section{RESULTADOS}

CONCLUSIONES. Aquí se presenta la copia textual de las mismas tomada del "Informe preliminar oficial" de la Conferencia que apareció en el Boletín de la UNESCO para las bibliotecas. (20)

La única modificación es que se ha separado la Exposición de Principios contenida en la primera conclusión a fin de destacarlos.

\section{CONCLUSIÓN I}

La Conferencia aprueba, de acuerdo con los votos registrados en otra parte, la exposición de principios que se inserta más adelante.

Se ruega a los delegados oficiales nacionales y a las comisiones nacionales:

3.1.Que procuren la divulgación más amplia posible de este texto entre los bibliotecarios, editores y libreros, así como las autoridades responsables de sus respectivos países;

3.2. Que tomen las medidas necesarias para asegurar:

3.2.1.que las reglas de catalogación de sus países se establezcan - revisen tan pronto como sea posible de conformidad con los principios declarados en la Conferencia y que se pongn en práctica;

3.2.2.que los mismos principios se tengan en cuenta en la redac- ción de las bibliografías nacionales.

También se pide a los delegados oficiales de las organizaciones internacionales que den cuenta del texto de la Exposición de Principios a los miembros nacionales de sus organizaciones. Igualmente se ruega a la secretaría que comunique el texto de la Exposición de Principios a todos los países no representados en la Conferencia así como a cualquier organización internacional no representada que juzgue pueda estar interesada en los problemas de catalogación.

\section{CONCLUSIÓN II}

La Conferencia acuerda:

1. Que su Comisión organizadora, con su actual ampliación, permanezca constituida hasta la próxima reunión anual del Consejo de la FIAB, a los efectos de:

1.1.hacer las correcciones editoriales necesarias en los textos adoptados por la conferencia;

1.2.distribuir estos textos entre todos los delegados y observadores y entre todas las comisiones nacionales y otras organizaciones participantes, así como a la prensa profesional;

1.3.editar y publicar el informe de la Conferencia; 1.4. asegurar la ejecución de todas las conclusiones de la conferencia;

1.5.asegurar la continuación del trabajo emprendido en el curso de la Conferencia por los grupos especiales:

1.6.conservar y utilizar el material documental acumulado durante la preparación de la Conferencia y durante la Conferencia misma;

1.7.someter a la directiva de la FIAB una lista de otros temas de estudio en el campo de la catalogación.

2. Pedir a la directiva de la FIAB que considere la forma de conti- 
nuar el trabajo de la conferencia y otros temas de estudio en el campo de la catalogación, y que busque recursos económicos para realizar los proyectos aprobados por la Conferencia y los que requiera cualquier programa futuro.

\section{CONCLUSIÓN III}

La Conferencia considera que, en interés de una futura actividad internacional, las corporaciones nacionales creadas para los fines de la Conferencia, permanezcan constituidas y continúen cooperando con la Comisión Organizadora.

\section{CONCLUSIÓN IV}

Proyectos a realizar:

A. La Conferencia propone que se realicen los siguientes proyectos dirección de la Comisión Organizadora:

1. La publicación, en un plazo mínimo, de las normas aprobadas en cada país sobre el encabezamiento de los nombres personales de los autores nacionales.

2. La preparación y publicación de las listas siguientes:

2.1. una lista de encabezamientos aprobados por los nombres de Estados y otros organismos con jurisdicción territorial, de acuerdo con los nombres oficiales usados por estos mismos organismos y con sus equivalentes en las principales lenguas del mundo;

2.2. una lista de títulos uniformes para las obras clásicas anónimas de cada país, con sus equivalentes aprobados en las lenguas de otros países;

2.3. una lista restringida de categorías de publicaciones, a las que se les pueda asignar un encabezamiento convencional que refleje la forma de la obra.

B. La conferencia, observando la conveniencia de establecer ciertas listas de encabezamientos uniformes -por ejemplo de autores clásicos griegos y latinos, de nombres de las organizaciones internacionales importantes- propone la compilación de un número restringido de tales listas, a modo de experimento.

\section{CONCLUSIÓN V}

La Conferencia recomienda que aquellos países que compartes por completo o respecto a una parte de sus habitantes, el uso de una lengua común, se consulten con vista a la unificación de sus reglas en cuanto a la palabra inicial de los nombres personales de esa lengua.

\section{CONCLUSIÓN VI}

La Conferencia recomienda que la FIAB, en cooperación con otras organizaciones internacionales interesadas, estudie las posibles repercusiones en las reglas de catalogación derivadas del uso de maquinaria electrónica y de procedimientos mecánicos en general, especialmente en grandes bibliotecas generales.

\section{CONCLUSIÓN VII}

La Conferencia pide que se tome en consideración la posibilidad de añadir a la Exposición de Principios cierto número de puntos sobre los que sea posible un acuerdo internacional.

\section{CONCLUSIÓN VIII}

La Conferencia ve complacida el espíritu de cooperación reafirmado por el delegado de la Organización Internacional de Normalización (ISO), y espera que se mantendrá el contacto más estrecho entre la FIAB e ISO, particularmente en lo que se refiere a las referencias bibliográficas y a la transliteración.

CONCLUSIÓN IX 
La Conferencia hace constar que, si ha logrado su objetivo y ha llegado a un extenso acuerdo en principios de catalogación, debe este éxito a los amplios medios puestos a la disposición de la FIAB por el Council on Library Resources. Esta ayuda ha hecho posible llevar a cabo los preparativos para la Conferencia bajo excelentes condiciones y reunir a expertos responsables de un gran número de países y organizaciones internacionales.

La Conferencia expresa su gratitud al Council on Library Resources por su generosa ayuda.

\section{EXPOSICIÓN DE PRINCIPIOS*}

\section{ALCANCE DE LA EXPOSICIÓN}

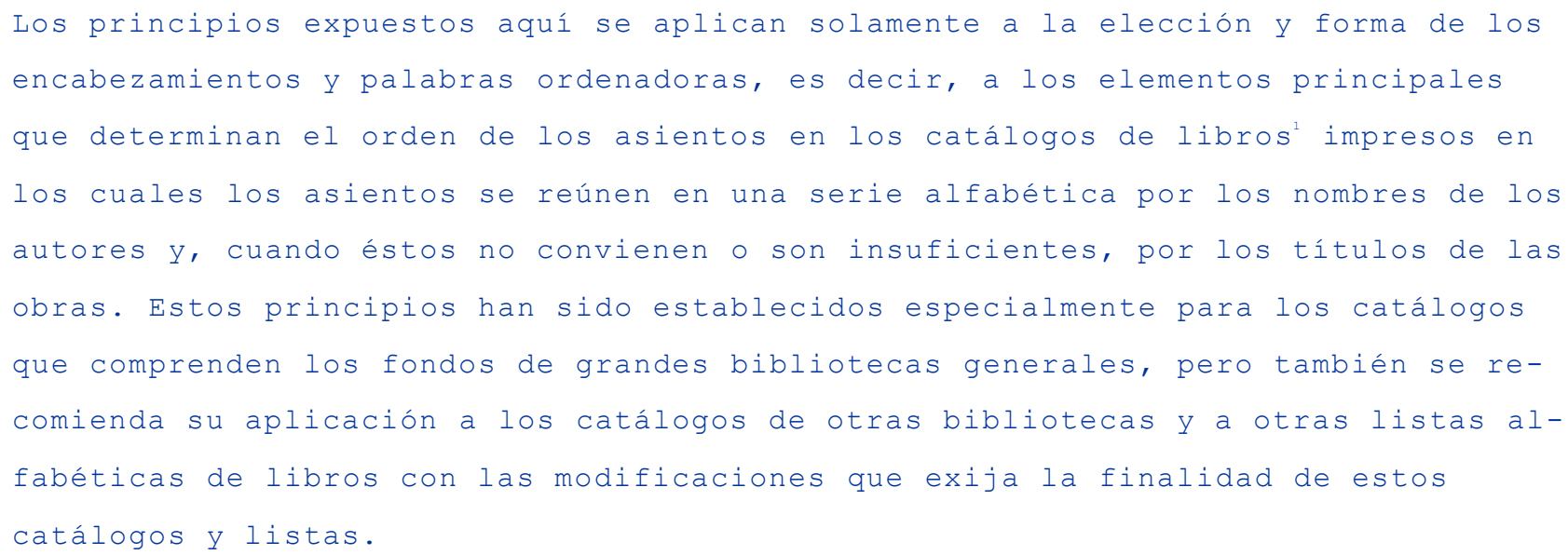

\section{FUNCIONES DEL CATÁLOGO}

El catálogo debe ser un instrumento eficaz para averiguar:

2.1.si la biblioteca contiene un libro determinado especificado por

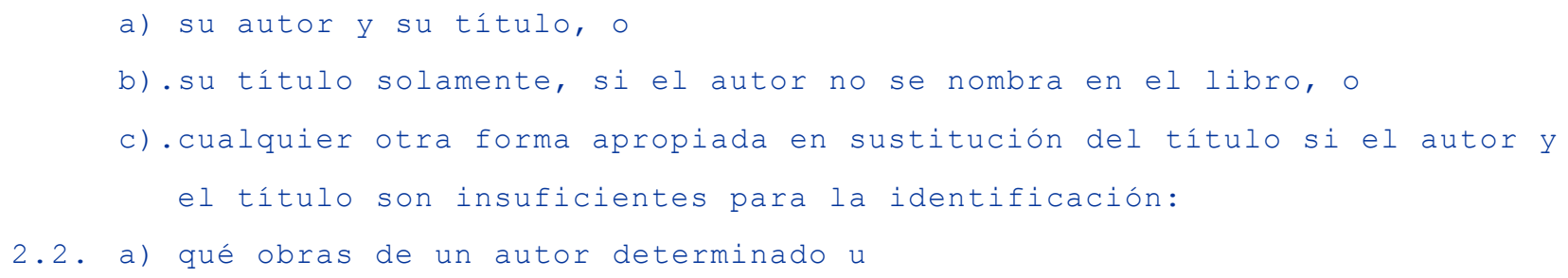

* Recuérdese que es una copia textual, por tanto, se han respetado la numeración de las notas de pie de página para efectos de la presentación de los Principios.

1 En esta Exposición la palabra "libro" abarca, también, otros materiales bibliográficos que presenten características parecidas. 
b) qué ediciones de una obra determinada figuran en la biblioteca.

\section{ESTRUCTURA DEL CATÁLOGO}

Para cumplir estas funciones el catálogo debe contener:

3.1. por lo menos un asiento para cada libro catalogado, y

3.2. más de un asiento para cualquier libro siempre que sea necesario en interés

del lector o por las características del libro -por ejemplo:

3.2.1 cuando el autor es conocido por más de un nombre o forma de nombre, o

3.2.2 cuando el nombre del autor ha sido averiguado, pero no consta en la portada del libro, o

3.2.3 cuando varios autores o colaboradores han participado en la creación del libro, o

3.2.4 cuando el libro se atribuye a varios autores, o

3.2.5 cuando el libro contiene una obra conocida por varios títulos.

\section{CLASES DE ASIENTOS}

Los asientos pueden ser de las clases siguientes: asientos principales, asientos secundarios y referencias.

4.1. Debe haber un asiento completo para cada libro, el asiento principal, que contenga todos los datos necesarios para identificar el libro. Puede haber otras dos clases de asientos: asientos secundarios (es decir, asientos suplementarios basados en el asiento principal y que reproducen bajo otros encabezamientos la información contenida en aquél) o referencias (que remiten al lector a otro lugar del catálogo).

\section{EMPLEO DE ASIENTOS MÚLTIPLES}

Las dos funciones del catálogo (véase 2.1 y 2.2) se consiguen del modo más eficaz por:

5.1 un asiento para cada libro bajo un encabezamiento tomado del nombre del autor o del título tal como figura en el libro.

5.2 cuando el nombre del autor o el título aparecen en distintas formas, un 
asiento para cada libro bajo un encabezamiento uniforme ${ }^{2}$ consistente en una forma determinada del nombre del autor o en un título determinado o, para los libros no identificados por el autor o por el título, un encabezamiento uniforme consistente en una forma apropiada que sustitu ya al título, y

5.3 asientos secundarios adecuados o referencias, o bien ambos.

\section{FUNCIÓN DE LAS DIFERENTES CLASES DE ASIENTOS}

6.1 El asiento principal de las obras catalogadas por los nombres de los autores debe ser, normalmente, un encabezamiento uniforme. El asiento principal de las obras catalogadas por el título puede ser o el título tal como figura en el libro con un asiento secundario del título uniforme o el título uniforme con asientos secundarios o referencias por los otros títulos. Se recomienda esta última práctica para la catalogación de obras muy conocidas, especialmente las que lo son por títulos tradicionales (véase 11.3).

6.2 Los asientos bajos otros nombres o variantes de nombre del mismo autor deben tomar, generalmente, la forma de referencias; pero, en casos especiales, se pueden emplear asientos secundarios. ${ }^{4}$

6.3 Los asientos bajo otros títulos de la misma obra deben tomar generalmente la forma de asientos secundarios; pero pueden usarse referencias cuando con ellas se logra sustituir a varios asientos secundarios bajo un encabezamiento.

6.4 Deben hacerse también asientos secundarios (o referencias en casos determinados) de los nombres de los coautores, colaboradores, etc. y de los títulos de las obras catalogadas por el nombre del autor, cuando el título sea también medio importante de identificación.

2 El término "encabezamiento uniforme" ha sustituido al de "encabezamiento standard" usado en el texto sometido a la Conferencia teniendo en cuenta la objeción de que el último término podría suponer un encabezamiento que ha recibido la aprobación de una organización normalizadora.

3 Los principios establecidos para las obras catalogadas por el título puede seguirse también al ordenar las fichas por el encabezamiento de autor determinado.

4 Por ejemplo, cuando un grupo determinado de obras está asociado a un nombre también determinado.

5 Por ejemplo, cuando una variante del título ha sido usada en cierto número de ediciones. 


\section{ELECCIÓN DEL ENCABEZAMIENTO UNIFORME}

El encabezamiento uniforme será generalmente el nombre (o forma de nombre) más usado o el título que aparezca más a menudo en las ediciones de las obras catalogadas o en las referencias tomadas de fuentes autorizadas.

7.1 Cuando las diversas ediciones han aparecido en varias lenguas debe darse la preferencia, en general, al encabezamiento tomado de las ediciones en el idioma original; pero si esta lengua no se emplea correctamente en el catálogo, el encabezamiento puede tomarse de las ediciones y referencias en una de las lenguas usadas normalmente en aquél.

\section{AUTOR PERSONAL ÚNICO}

8.1 El asiento principal para cualquier edición de una obra de un autor, persona física, se hará por el nombre del autor. Cuando el nombre del autor no conste en la portada se redactará un siento secundario o una referencia del título.

8.2 El encabezamiento uniforme será el nombre por el cual el autor es identificado más frecuentemente en las ediciones de sus obras en la forma más completa que aparezca en ellas, excepto que

8.2.1 otro nombre o forma de nombre deba ser considerado como encabezamiento uniforme si ha sido establecido por el uso general, bien por las referencias sobre el autor en obras biográficas, históricas y literarias, bien en relación con sus actividades públicas distintas de las de escritor.

8.22 Se añadirá algún dato suplementario de identificación, si es necesario, para distinguir al autor de otros del mismo nombre.

\section{ASIENTOS BAJO NOMBRES DE ENTIDADES}

9.1 El asiento principal de una obra se hará por el nombre de una entidad (es decir, cualquier institución, corporación organizada o reunión de personas conocidas por un nombre corporativo o colectivol.

6 Véase sección 7.1 
9.1.1 cuando la obra, por su naturaleza, es necesariamente la expresión del pensamiento o de la actividad colectiva de la entidad a nque esté firmada por una persona en calidad de funcionario o empleado de la entidad, o

9.1.2 cuando la redacción del título y de la portada considerados en relación con la naturaleza de la obra, indica claramente que la entidad es responsable colectivamente del contenido de la obra."

9.2 En otros casos, cuando una entidad ha asumido una función secundaria (tal como la de editor) en relación con la del autor, se redactará un asiento secundario por el nombre de la entidad.

9.3 En los casos dudosos, el asiento principal puede hacerse ya por el nombre de la entidad, ya por el título o por el nombre del autor, persona física, con un asiento secundario en uno y otro caso por la forma no escogida para el asiento principal.

9.4 En encabezamiento uniforme de las obras catalogadas por entidades será el nombre por el cual la entidad es más frecuentemente designada en sus publicaciones, salvo en los casos siguientes:

9.4.1 si el nombre de la entidad no aparece siempre en la misma forma en sus publicaciones, se elegirá como encabezamiento la forma oficial del nombre;

9.4.2 si existen nombres oficiales de la entidad en varias lenguas, el encabezamiento deberá ser el de la lengua que mejor responsa a las necesidades de los que han de utilizar el catálogo;

9.4.3 si la entidad es conocida generalmente por un nombre convencional, el encabezamiento uniforme será este nombre convencional en una de las lenguas normalmente empleadas en el catálogo;

9.4.4 el encabezamiento uniforme de los estados y demás organismos con jurisdicción territorial será el nombre con que se designe corrientemente

7 Por ejemplo, informes oficiales, reglas y reglamentos, manifiestos, programas y actas de los resultados de una obra colectiva.

8 Por ejemplo, publicaciones seriadas cuyos títulos consisten en un término genérico (boletín, memorias, etcétera) precedido o seguido del nombre de una entidad, y que incluye alguna información de las actividades de la corporación. 
el territorio de que se trate, en la lengua que mejor responda a las necesidades de los usuarios del catálogo:

9.4.5 si la entidad ha usado en épocas sucesivas nombres diferentes que no pueden ser considerados como ligeras variantes de uno sólo, el encabezamiento de cada obra será el nombre que la entidad tenía en el momento de su publicación y se establecerá la debida relación entre los diversos nombres por medio de referencias; ${ }^{9}$

9.4.6 se agregará alguna característica que facilite la identificación, cuando sea necesario, para distinguir a la entidad de otras del mismo nombre.

9.5 Las constituciones, leyes y tratados, así algunas otras obras que tiene características similares, se catalogarán por el nombre del respetivo Estado o autoridad, con títulos formales o convencionales que indiquen la naturaleza del material de que se trata. En caso necesario se harán asientos secundarios por los títulos que figuren en las obras.

9.6 Las obras de una entidad subordinada a otra superior se catalogarán por el nombre de la entidad subordinada, salvo en los casos siguientes:

9.6.1 i ese nombre implica en sí mismo una subordinación o función subalterna o no basta para identificar a la entidad subordinada, el encabezamiento será el nombre de la entidad superior, con el de la subordinada como subencabezamiento.

9.6.2 si la entidad subordinada es un órgano administrativo, judicial o legislativo de un Estado o de otro organismo con jurisdicción territorial, se tomará como encabezamiento el nombre del mismo y se añadirá como subencabezamiento el nombre del órgano de que se trate.

9 Si se tiene la seguridad de que los nombres sucesivos designan la misma entidad, se podrá admitir también la solución de agrupar todos los asientos bajo el último nombre empleado, con referencias de los demás. 


\section{AUTORES MÚLTIPLES}

Cuando dos o más autores ${ }^{10}$ han colaborado en la creación de una obra:

10.1 si uno de ellos figura en el libro como autor principal y los demás desempeñan un papel subordinado o auxiliar, se catalogará la obra por el nombre de ese autor principal.

10.2 si ninguno de ellos figura en el libro como autor principal, la obra se catalogará:

10.2.1 por el autor mencionado en primer ligar en la portada si se trata de dos o tres autores, y se harán asientos secundarios por el nombre o nombres de los restantes;

10.2.2 por el título de la obra si los autores son más de tres, con asientos secundarios por el nombre del autor que figure en primer lugar en el libro y por tantos de los restantes autores como se considere necesario.

\subsection{Colecciones ${ }^{11}$}

El asiento principal de una colección formada por obras independientes o partes de obras de diferentes autores, se hará:

10.31 por el título de la colección, si ésta tiene un título colectivo;

10.32 por el nombre del autor o el título de la primera obra de la colección, si ésta no tiene título colectivo;

10 En esta sección, el concepto de "autor" comprende también las entidades bajo cuyo nombre se hacen asientos. (Véase sección 9). 11 Una minoría relativamente importante de la conferencia no aceptó el texto aprobado que figura con el número 10.3 y otorgó sus votos al siguiente, que se había presentado como alternativa: 10.3 el asiento principal de una colección formada por obras independientes o partes de obras de diferentes autores se hará: 10.3.1 si la colección tiene título colectivo

10.31.1 por el nombre del compilador (es decir, de la persona que ha reunido los materiales de la colección, sacándolos de varias fuentes) si figura en la portada. 10.31.2 por el título de la colección si el nombre del compilador no figura en la portada:

10.3.2 si la colección no tiene título colectivo, por el nombre del autor o por el título de la primera obra de la colección.

10.3.3 se hará siempre un asiento secundario por el nombre del compilador, si se conoce, cuando no haya sido escogido para encabezamiento del asiento principal; y por el título, si el asiento principal se ha hecho por el compilador. 
10.33 en ambos casos, si se conoce el nombre del compilador (es decir, de la persona que ha reunido los materiales de la colección, sacándolos de varias fuentes), se hará de él un asiento secundario.

10.34 Excepción: si el nombre del compilador se destaca claramente en la portada, puede hacerse por él el asiento principal con otro secundario por el título.

10.4 Si las partes sucesivas de una obra son de diferentes autores, el asiento principal se hará por el nombre del autor de la primera parte.

\section{OBRAS CATALOGADAS POR EL TÍtULO}

11.1 Tendrán un asiento principal por el título:

11.11 las obras cuyos autores no hayan sido averiguados;

11.12 las obras escritas por más de tres autores, si ninguno de ellos figura como autor principal (véase 10.22);

11.13 las colecciones de obras independientes o partes de obras de diferentes autores, publicadas con un título colectivo;

11.14 las obras (incluso series y revistas) conocidas principal o convencionalmente por el título más que por el nombre del autor.

11.2 Deberá hacerse un asiento secundario o una referencia por el título para: 11.21 las ediciones anónimas de obras cuyos autores hayan sido averiguados: 11.22 la sobras cuyo asiento principal haya sido hecho por el nombre del autor, cuando el título constituya otro importante medio de identificación;

11.23 las obras cuyo asiento principal haya sido hecho por el nombre de una entidad, pero que tengan títulos en los que no figure expresamente ese nombre ;

11.24 las colecciones cuyo asiento principal se haga, excepcionalmente, por el nombre del compilador.

11.3 El encabezamiento uniforme (para asientos principales o secundarios, (véase 6.1) de obras que se catalogan por el título, debe ser el título original o

el título más frecuentemente usado en las ediciones de la obra, ${ }^{12}$ excepto: 
11.31 si la obra es generalmente conocida por un título convencional, el título convencional será el encabezamiento uniforme.

11.4 El encabezamiento uniforme de obras cuyas partes sucesivas o volúmenes llevan títulos diferentes, debe ser el título de la primera parte, a no ser que la mayoría de las partes o volúmenes lleven otro título.

11.5 Cuando una publicación seriada se ha editado sucesivamente bajo diferentes títulos, debe hacerse un asiento principal por cada título para aquellos fascículos que lleven este título, con la indicación, por lo menos, del título anterior y posterior. De cada una de estas series puede hacerse un asiento secundario bajo un título elegido. ${ }^{13}$ Sin embargo si las variaciones en el título son ligeras, puede adoptarse la forma más frecuentemente usada como encabezamiento uniforme para todas las publicaciones.

11.6 Los tratados y convenciones internacionales multilaterales y cualesquiera otras clases de publicaciones editadas con títulos no definidos, pueden catalogarse bajo un encabezamiento uniforme convencional que refleje la forma de la obra. ${ }^{1}$

\section{PALABRA INICIAL PARA EL ENCABEZAMIENTO DE LOS NOMBRES PERSONALES}

Cuando el nombre de un autor personal se compone de varias palabras, la elección de la palabra inicial se determina, en cuanto sea posible, por el uso establecido en el país del que el autor es ciudadano, o, si esto no es posible, por el uso establecido en la lengua que generalmente usa.

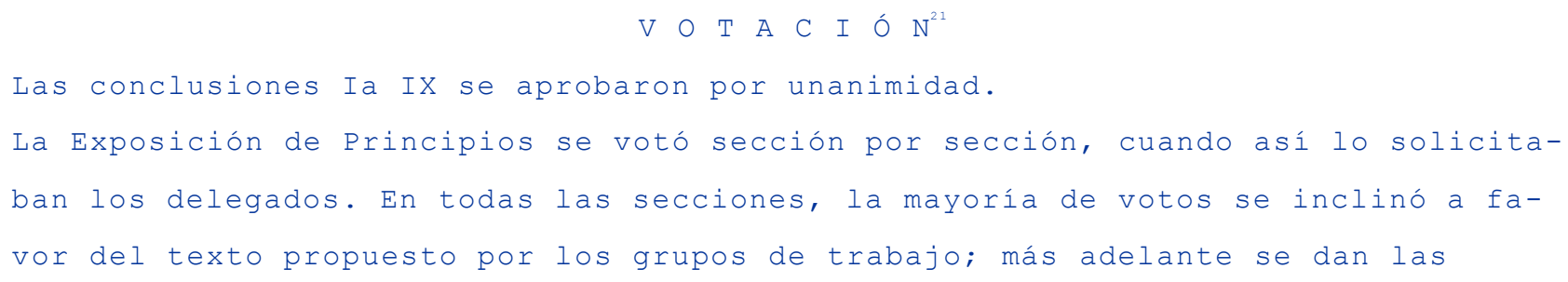


cifras de los votos separados. (Los detalles de los votos en contra y abstenciones, con las observaciones de algunos delegados, se incluirán en el informe completo de la Conferencia). Los representantes de la FIAB y la Unión Internacional de Editores no tomaron parte en la votación.

Hasta aquí se ha procurado presentar el desarrollo de la Conferencia. Lo relativo a la influencia que la exposición de principios tuvo en la elaboración del

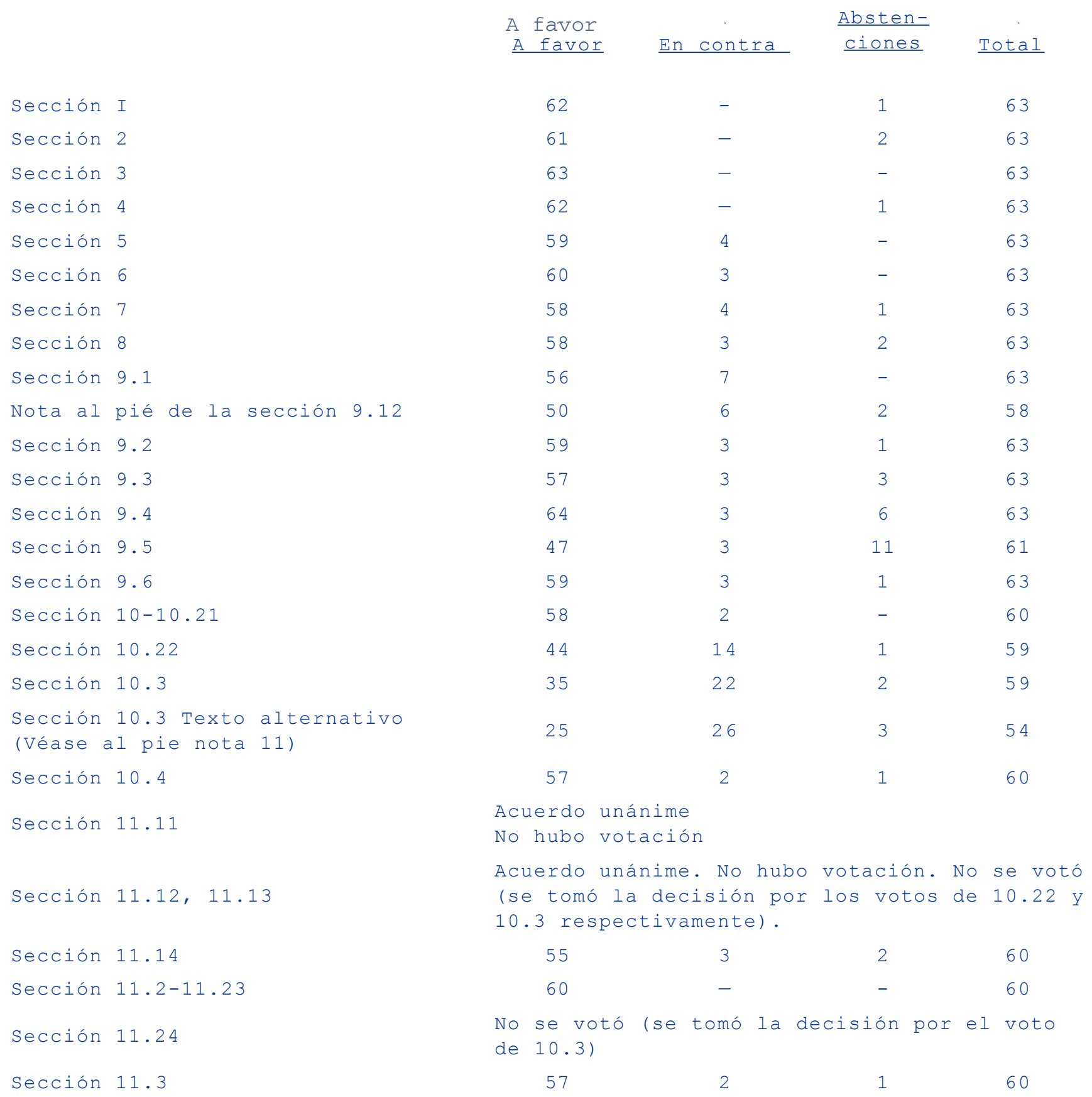




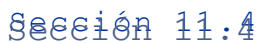

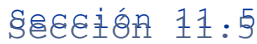

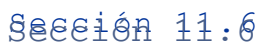

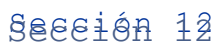

60

54

5를

54
$=$

4

5

5
80

80

80

8 王

Código Angloamericano y en la revisión y actualización del código español -por citar solo dos ejemplos- se reservan para un escrito posterior a fin de no hacer demasiado extenso el presente artículo.

\section{CITAS BIBLIOGRÁFICAS}

${ }^{1}$ CIPC. "Informe preliminar oficial".

ªnderson. "Normalización internacional de la catalogación y los registros bibliográficos". P. 70

${ }^{3}$ LoC. Cit.

${ }^{4}$ CIPC. "Informe preliminar oficial". p. 57

${ }^{5}$ LoC. Cit.

LoC. Cit

"Conf. Int. de Cat. Reunión Prel. "Informe". - p. 271-275.

${ }^{8}$ CIPC. "Informe preliminar oficial". p. 57

Ibid. p. 66

I0 Ibid. P. 67

Ibid. p. 66

${ }^{12}$ Poves B. "La Conferencia Internacional sobre Principios de Catalogación". P. $34-35$

${ }^{13}$ CIPC. "Informe preliminar oficial". p. 67

${ }^{14}$ Poves B. p. 35

${ }^{15}$ CIPC. Report. P. V-vi la información acerca de los documentos de trabajo se tomó de Poves B. p. 35-36

${ }^{16}$ Poves B. p. 36

${ }^{17}$ Ibid. p. $29-34$

${ }^{18}$ CIPC. $\underline{\text { Report p. } 281-290}$

${ }^{19}$ Wright. "Las reglas angloamericanas de catalogación". H. 12

${ }^{20} \mathrm{CIPC}$. "Informe preliminar oficial".

${ }^{21}$ Ibid. p. 65 


\section{OBRAS CONSULTADAS}

ANDERSON, Dorothy. "Normalización internacional de la catalogación y los registros bibliográficos : el trabajo del Comité de Catalogación de la FIAB". -p. 7076. -En Boletín de la UNESCO para las bibliotecas. - vol. XXVII, no. 2 (marzo-abril 1973)

BALL, Catherine. "The Paris conference". - p. 172-175. - En Library Resources and Technical Services. - vol. 6 no. 2 (Spring 1962)

CONFERENCIA INTERNACIONAL DE CATALOGACIÓN. REUNIÓN PRELIMINAR (1959 : LONDRES) "Informe". - p. 271-275. - En Boletín de la UNESCO para las Bibliotecas. - vol. XIII, no. 11-12 (nov.-dic. 1959)

CONFERENCIA INTERNACIONAL SOBRE LOS PRINCIPIOS DE CATALOGACIÓN (1961: PARÍS) Exposición de principios / Edit. por A. H. Chaplin con la asistencia de Dorothy Anderson. - Ed. prov. tr. De la vers. Francesa por Aída Opazo. - Caracas : Universidad Central de Venezuela, 1969. - pag. varía.

- - - - "Informe preliminar oficial2. - p. 57-68. - En Boletín de la UNESCO para las bibliotecas. - vol. XVI, no. 2 (marzo-abril 1962)

- - - - Report / Ed. by a. H. Chaplin and Dorothy anderson. - London : IFLA, Organizing Committee of the International Conference on Cataloguing Principles, National Central Library, 1963. - viii, 293 p.

POVES BARCENAS, María Luisa. "La Conferencia Internacional sobre Principios de Catalogación". - p. 27-36. - En Boletín de la Dirección General de Archivos y Bibliotecas. - Madrid : La Dirección. - vol. 10, no. 52, 1961.

WRIGHT, Wyllis E. "Las reglas angloamericanas de catalogación : perspectiva histórica". - 20 h. "Traducción del inglés para Azcapotzalco" Traducción sin revisar de "The Anglo-american cataloging rules : historic view" aparecido en Library resources and Technical services, vol. 20, 1975, p. 36-47. 